\title{
LOS JUEGOS TRADICIONALES Y LA EDUCACIÓN EN CANARIAS: DE LAS PROPUESTAS DEL SIGLO XIX A LAS REGULACIONES AUTONÓMICAS
}

\section{Traditional games and education in the Canary Islands: from Ioth century proposals to autonomic legal texts}

Antonio S. Almeida Aguiar

Departamento de Educación. Área de Teoría e Historia de la Educación

Universidad de Las Palmas de Gran Canaria

Correo-e: antonio.almeida@ulpgc.es

Ulises S. CASTRO NúÑEZ

Departamento de Educación Física

Universidad de Las Palmas de Gran Canaria

Correo-e: ulises.castro@ulpgc.es

Recepción: io de noviembre de 2018. Envío a informantes: I9 de noviembre de 2018 Aceptación definitiva: 22 de enero de 2019

Resumen: Una de las claves metodológicas de la educación contemporánea, después de los cambios que se produjeron a partir de la renovación pedagógica del siglo xIx, es la incorporación del juego como base de la enseñanza, especialmente en las primeras edades del desarrollo del ser humano. Una de las modalidades lúdicas que nos ha interesado para el presente estudio son los denominados juegos tradicionales. Partiendo de un análisis conceptual que trata de delimitar las características de los juegos tradicionales, hemos realizado una aproximación a los mismos desde las primeras propuestas generales planteadas por intelectuales, muchos de ellos vinculados al movimiento regeneracionista en las islas, hasta las regulaciones autonómicas que incluyen estos juegos dentro del currículum educativo. Para conseguir 
estos objetivos, hemos utilizados fuentes primarias, tanto de la prensa general como de la prensa pedagógica, especialmente del siglo xix, así como textos legales, decretos y disposiciones que articulan los juegos tradicionales en la enseñanza en Canarias del siglo XXI.

Palabras clave: juegos tradicionales; prensa pedagógica; Canarias; cultura; Historia de la Educación.

Aвstract: One of the methodological keys of contemporary education, after the changes that occurred during the pedagogical renewal of the nineteenth century, is the incorporation of the game as the teaching ground, especially in the early ages of human development. One of the ludic modalities that has interested us for the present study are the so-called traditional games. Starting from a conceptual analysis that tries to delimit the characteristics of traditional games, we have made an approximation to them from the first general proposals raised by intellectuals, many of them linked to the regeneracionismo movement in the islands, up to the autonomic regulations that include these games within the educational curriculum. To achieve these objectives, we have used primary sources, both from the general press and the pedagogical press, especially from the igth century, as well as legal texts, decrees and provisions that articulate traditional games in teaching in the 2Ist century in the Canary Islands.

KEY WORDs: traditional games; pedagogical press; Canary Islands; culture; History of Education.

\section{Introducción}

$\mathrm{U}$ NA DE LAS PROBlemáticas FUndamentales de todo objeto científico es su conceptualización. La diversidad de disciplinas científicas que abordan una misma temática de estudio, sin duda, puede dificultar, más que esclarecer, los criterios que pueden ayudar a la definición de dicho campo de estudio. Sin embargo, estos análisis son esenciales para ir delimitando el objeto al que nos referimos. Para Bunge «desde un punto de vista lógico, los conceptos son las unidades mínimas de pensamiento científico» ${ }^{ }$. Su validez se derivaría de su sistematicidad y, cuando la teoría científica a la que pertenecen es refutada, no tienen por qué correr la misma suerte que aquella. Aunque nuestro objetivo no es establecer un estudio de las distintas clasificaciones del concepto juego, sí queremos indicar que, a finales del siglo xix, varios antropólogos, entre los que podemos citar a Morgan y Taylor, establecieron en su momento la siguiente: a) juegos de habilidad física, en los que el éxito se determina por las actividades motrices de los jugadores; b) juegos de estrategia, en los que el éxito se determina por la opción racional entre varios tipos de acción posible, y c) juegos de azar, en los que

Bunge, M.: La investigación cientifica, Barcelona, Ariel, 1985, p. 182. 
LOS JUEGOS TRADICIONALES Y LA EDUCACIÓN EN CANARIAS: DE LAS PROPUESTAS DEL SIGLO XIX A LAS REGULACIONES AUTONÓMICAS ANTONIO S. ALMEIDA AGUIAR Y ULISES S. CASTRO NÚÑEZ

el éxito se determina por adivinanzas o por un artefacto incontrolado como una rueda o un dado ${ }^{2}$. No obstante, como punto de inicio, suele ser habitual para el análisis del concepto juego la definición que Huizinga realizó en los años treinta del pasado siglo:

Acción o actividad libre, realizada dentro de ciertos límites fijados en el tiempo y en el espacio, según una regla libremente aceptada, pero completamente imperiosa; acción que tiene fin en sí misma y que va acompañada de tensión y alegría y con la conciencia de ser de otra manera a la que se es en la vida corriente 3 .

Sin embargo, esta definición ha sido cuestionada por los enfoques sociológicos y culturales, sobre todo por su carácter idealista. Desde nuestro punto de vista, en el juego tradicional se incorporan otros rasgos de mayor carga sociocultural. Por esta razón, debemos definir el juego de una manera más global, aunque reconocemos que su construcción tiene unas enormes dificultades operativas. Siguiendo este argumento integrador del juego, puede ser considerado también como un fenómeno universal, que ha ido parejo al ser humano desde el inicio de los tiempos ${ }^{4}$. Los cambios históricos, sociales, políticos, religiosos han afectado al juego en la medida en que se trata de cultura. Como dicen Blanchard y Cheska: «El juego es una forma de comportamiento que incluye tanto dimensiones biológicas como culturales $[\ldots] »$.

Los distintos enfoques mencionados permiten entender la inexistencia de un consenso general sobre la definición de juego. No obstante, utilizando una línea de interpretación multidisciplinar, es posible elaborar unos rasgos que permitan acercarnos a lo que es juego. Desde esta perspectiva, autores como Hernández, Castro y Navarro conciben el juego como «una actividad recreativa de incertidumbre sometida a un contexto sociocultural $»^{6}$. Lo verdaderamente relevante del concepto de juego, aparte de su concepción global, está en los rasgos que caracterizan a la modalidad de juego de nuestro interés: el juego motor distinguido por la tradición. Estas actividades son reconocidas mediante diversas denominaciones: juegos autóctonos, juegos populares, juegos tradicionales, juegos vernáculos e incluso juegos folclóricos. Todas ellas se caracterizan por constituir parte del acervo cultural y de la identidad de una comunidad, como señala Barreto:

El amplio catálogo de prácticas y juegos tradicionales presentes en las Islas Canarias permite distinguirlo como importante marcador simbólico en la construcción

Blanchard, K. y Cheska, A.: Antropología del deporte, Barcelona, Bellaterra, 1986.

Huizinga, J.: Homo ludens, Madrid, Alianza, 1984, p. 26.

4 CASTro, U.: Estudio etnográfico y de la lógica de las situaciones motrices de un juego tradicional desaparecido: la pina, tesis doctoral, Las Palmas de Gran Canaria, Universidad de Las Palmas de Gran Canaria, 200I.

Blanchard, K. y Cheska, A.: op.cit., p. 29.

6 Hernández, J.; Castro, U. y Navarro, V.: Los juegos y deportes tradicionales de Canarias, Las Palmas de Gran Canaria, Consejería de Educación, Cultura y Deportes, Universidad de Las Palmas de Gran Canaria, 2003, p. I4I. 
de la identidad canaria con una cultura propia. Podemos decir así, que los juegos y deportes tradicionales de Canarias son importantes elementos que dan explicación a la identidad cultural de los canarios?

Lo «tradicional» es lo «perteneciente o relativo a la tradición, o que se transmite por medio de ella; definiéndose «tradición» como «transmisión de noticias, composiciones literarias, doctrinas, ritos, costumbres, etc., hecha de generación en generación// Noticia de un hecho antiguo transmitida de ese modo// Doctrina, costumbre, etc. conservada en un pueblo por transmisión de padres a hijos». El término «tradicional» hace referencia a la «transmisión de ritos, costumbres, [juegos] hecha de generación en generación, costumbre que se ha conservado y se ha transmitido en el grupo durante generaciones» ${ }^{8}$. Preguntándonos cuántas generaciones son necesarias para adquirir el calificativo de tradicional:

Pensamos que tres generaciones son suficientes para ello porque si durante éstas una actividad se ha mantenido y traspasado de padres a hijos significa que el grupo la ha hecho suya, que ha pasado a formar parte de sus patrones de conducta y de relación intergeneracional, y no es una mera moda pasajera?.

Otro rasgo que está íntimamente ligado a la tradición es lo oral, el aprendizaje no premeditado o consciente, de una asimilación por observación. Son acciones o situaciones lúdicas con las que el niño convive diariamente y que va integrando. El niño observa a los otros niños más grandes o a los adultos, copia sus materiales de juego e imita sus acciones, hasta que llega el día en que participa del juego común. Según Castro, el juego tradicional es una actividad lúdica, generalmente de carácter motor, que se ha transmitido de generación en generación dentro del grupo en el que se manifiesta y que está íntimamente ligada al contexto sociocultural en el que se desarrolla, al tiempo que se adapta a las necesidades y posibilidades de cada momento ${ }^{\text {Io }}$. Las definiciones del concepto juego tradicional son muy heterogéneas, aunque todas ellas hacen referencia al hecho cultural o de socialización que implican. Generelo y Planas lo caracterizan como «juego practicado por generaciones, dentro de una comunidad más o menos grande, que se encuentra arraigado en una cultura dada y que por lo tanto nos habla de la forma de ser y de sentir de la gente de esa región $»^{\text {II }}$. Finalmente, creemos oportuno destacar las características de los juegos tradicionales que Trigueros enumera como

BARreto, M.: «Construyendo identidades: juegos y deportes tradicionales canarios», en AmADor, F. y otros: Luchas. Deportes de combate y juegos tradicionales, Madrid, Gymnos, 1996, p. 24.

8 Castro, U.: Estudio etnográfico..., op. cit., p. 96.

9 CAstro, U.: «Del juego a la lúdica tradicional: el caso de Canarias», en Recuerdos y Sensaciones. Álbum Artístico del Deporte, Las Palmas de Gran Canaria, Universidad de Las Palmas de Gran Canaria, 2004, pp. 63-89.

Io Ibidem.

" Generelo, E. y Planas, C.: «Cuéntame yayo: un ejemplo de material didáctico como apoyo a la formación del maestro acerca de los valores pedagógico de los juegos tradicionales», en AmADOR F. y otros: Luchas. Deportes de combate y juegos tradicionales, Madrid, Gymnos, 1996, p. 745. 
LOS JUEGOS TRADICIONALES Y LA EDUCACIÓN EN CANARIAS: DE LAS PROPUESTAS

DEL SIGLO XIX A LAS REGULACIONES AUTONÓMICAS

ANTONIO S. ALMEIDA AGUIAR Y ULISES S. CASTRO NÚÑEZ

forma de diferenciación de otros tipos de juego, puntualizando los rasgos más importantes que están presentes ${ }^{12}$.

\section{CARACTERÍSTICAS JUEGOS TRADICIONALES (TRIGUEROS 2000 )}

I. Estar plenamente integrados en el entorno, tanto que no se suele hacer referencia a espacios específicos, y donde el juguete, cuando es necesario para el desarrollo del juego, suele ser un material presente en el entorno transformado para la actividad lúdica.

2. Poseer reglas y condiciones cambiantes, precisamente por la necesidad de adaptarse al medio o a las circunstancias concretas en las que va a ser practicado.

3. El juego, por el hecho de carecer de reglas fijas y estar integrado en el entorno, puede ser recreado constantemente, apareciendo continuamente nuevas variantes de determinados juegos.

4. El juego tradicional no solo es juego. Cuando un juego tradicional es realizado importa tanto todo lo que rodea al juego, como el juego en sí. Desde la propia elección de jugadores, como las actitudes y relaciones de los mismos, así como la lengua utilizada, todo forma parte de la escenificación del juego, siendo imprescindible para contar y analizar el propio juego.

5. Los juegos tradicionales infantiles, de los niños y niñas, son, en su esencia, imitaciones del trabajo del adulto (en la mayoría de los casos).

6. Nacidos en sociedades que precisan actividades lúdicas para sus miembros, existen juegos tradicionales para todas las edades.

7. La principal función del juego tradicional es procurar la enculturación de los individuos nuevos en la sociedad; siendo este el verdadero sentido de los mismos.

\section{Primeras referencias en la prensa de los juegos en la educación contemporánea de las Islas Canarias}

Las ideas educativas defendidas en la segunda mitad del siglo xIx desde las iniciativas de Escuela Nueva, representadas en nuestro país principalmente por la Institución Libre de Enseñanza (ILE, I876), empiezan a tener repercusión en los sectores más progresistas de las Islas Canarias, que ven en estas acciones educativas elementos para cambiar el preocupante contexto escolar de la época. Aspectos como la coeducación, la función docente, el paidocentrismo, la renovación metodológica, la escuela neutra, la educación en la naturaleza, la educación física, los juegos, etc., formarán parte del discurso pedagógico de algunos maestros locales. En este ambiente de cambio y preocupación educativa hay que insertar iniciativas como la incorporación de los juegos en el ámbito escolar. Ya la ILE entendía el juego desde una perspectiva antropológico-cultural, en el sentido de pertenencia a la cultura del pueblo, a su masa social. De ahí que el interés por la práctica física defendida por los institucionistas tuviese cabida no solo los deportes o juegos ingleses, de los que Giner de los Ríos fue un gran defensor, sino también los

12 Trigueros, C.: Nuevos significados del juego tradicional en el desarrollo curricular de la educación física en centros de Educación Primaria en Granada, tesis doctoral, Granada, Universidad de Granada, 2000, p. II8. 
juegos tradicionales españoles, representantes de la cultura. Voces cercanas a la ILE orientaban la labor del educador en torno al juego: «El papel del educador consiste pues, en buscar todos los medios para que la actividad de los discípulos pueda manifestarse sin peligro alguno; los juegos colectivos al aire libre responden a esta condición» ${ }^{13}$.

En una misma línea educativa, la labor de Ferrière con la creación de la Oficina Internacional de Escuelas Nuevas (I899), y el posterior establecimiento de sus principios educativos (I919), es sin duda programática. En el principio noveno, ya se destaca que «el cultivo del cuerpo estará asegurado, tanto por la gimnasia natural, como por los juegos y deportes». Siguiendo esta idea, en el principio decimoquinto se especifica que «la enseñanza se basará en general sobre el espontáneo interés del niño; de cuatro a seis años, [...] edad del juego; de siete a nueve años, edad del interés adscrito a los objetos concretos inmediatos $[\ldots]]_{\gg^{14}}$. No obstante, se ha aceptado de forma general que el origen de los juegos calificados como educativos estaría relacionado con las escuelas pestalozzianas y froebelianas, las excelentes experiencias de Itard y Séguin en la educación especial, ampliadas y adaptadas a la educación preescolar por la doctora y pedagoga Montessori y Decroly. A ellos añadiríamos otros tantos, como Claparède, Piaget, Dewey o, más cercanas a nuestro país, las escuelas del Ave María. Para su fundador, el padre Manjón, uno de los cauces para alcanzar los objetivos educativos era aplicar el juego a la educación. Ante la ausencia de un «sistema de juegos pedagógicos», intentó aproximarse «al ideal de enseñar jugando, de educar haciendo» ${ }^{15}$, para así constituir a través de la experiencia un modelo lúdico de intervención educativa. En las escuelas del Ave María se trabajaba para «hacer juegos y juguetes, destinados a amenizar la enseñanza haciéndola más agradable e intuitiva, y sobre todo, más activa; porque si oír es adivinar lo que otro sabe, y ver es entender lo que otro hace, hacer será ver y entender» ${ }^{16}$. De esta manera, introduce, entre otros, algunos juegos tradicionales en la escuela: para aprender historia, emplea el juego de la rayuela o la gallina ciega; para la geografía, el mapamundi de relieve sumergido; para la lengua, el juego de la construcción con bloques de letras; para la matemática, el tablero contador, etc.

Uno de los principales canales de difusión que en el siglo XIX recoge reflexiones y propuestas en torno a los juegos y la educación en Canarias será la prensa local, especialmente la de las islas capitalinas. Además de la prensa diaria, también habrá editoriales en la prensa pedagógica y, en menor medida, en las revistas ilustradas de la época. Es el caso del artículo «Educación e Instrucción Primarias» (I88I), donde se hace una defensa de un sistema educativo libre, que llegue a todas las clases sociales, basado no solo en la instrucción, sino en la educación. Educación que debe partir del entorno familiar, por lo que la creación de «escuelas de padres

13 Rubio, R.: «Los juegos corporales en educación», BILE, 39I, pp. I45-I5O.

${ }_{14}$ Filho, L.: La escuela nueva, Barcelona, Labor, 1936, pp. I03-IO4.

is Manjón, A.: Lo que son las escuelas del Ave María. Modos de enseñar, Madrid, Patronato de las Escuelas del Ave María, 1948, p. 2II.

${ }_{16}$ Ibídem, p. I7I. 
LOS JUEGOS TRADICIONALES Y LA EDUCACIÓN EN CANARIAS: DE LAS PROPUESTAS

DEL SIGLO XIX A LAS REGULACIONES AUTONÓMICAS

ANTONIO S. ALMEIDA AGUIAR Y ULISES S. CASTRO NÚÑEZ

y madres» estaría entre los objetivos prioritarios. El juego aparece en este contexto como la base primaria de la educación física, con un fin pragmático, basado en teorías y principios prácticos que beneficiarían a la educación de la infancia. Estaría asociado, en este caso, al descubrimiento del propio cuerpo: «Para esto basta que comiencen a fijar la atención, a nombrar con conocimiento, a contar por los dedos, por las partes de su cuerpo, por los objetos que le rodean, por bolas o juguetes adecuados» ${ }^{17}$. Unos años más tarde, el folclorista Antonio Machado y Álvarez, padre del reconocido poeta de la generación del 27, utiliza las páginas de la revista El Museo Canario para escribir un interesante artículo con un doble objetivo: por un lado, dar a conocer la obra Saggio di guoghi e canti fanchulleschi (I878), del italiano Antonio Gianandrea; y, por otro, hacer una petición «a los ilustrados y simpáticos hijos de Canarias su eficaz y valiosa cooperación para un trabajo de igual índole que pienso publicar en breve» ${ }^{18}$. Con respecto al contenido de la obra de Gianandrea, Machado se centra principalmente en algunos juegos italianos y establece relaciones con los existentes en nuestro país. De esta manera, se nombran juegos tradicionales como anda la rueda, el diablo y los colores, las cuatro esquinas, la gallina ciega, el gato y el ratón, el esconder, la sillita o la silla de manos, el anillito, a la una anda la mula, la rayuela, etc. Con detenimiento, estudia en su artículo juegos como la campana, el juego del pico, el salto de Andreino, y otra serie de ejemplos. De entre ellos, destaca una serie de juegos en los que se introducen el ritmo, la poesía, el baile y la música, y que, sin duda, constituyen un marco ideal para dar los primeros pasos en la formación coral de la infancia. Además de relacionar el juego con la música como elemento esencial en la educación infantil, añade otra característica intrínseca al universo lúdico de la infancia, como es la imitación. De esta manera, el aprendizaje por imitación también encuentra en los juegos tradicionales un espacio adecuado para alcanzar aprendizajes significativos.

En los últimos años del siglo xIx, tendrán cabida en la prensa todas aquellas noticias referidas a las normativas y orientaciones que desde el ámbito de la «enseñanza gimnástica» se van dando en torno al juego. En este caso, las orientaciones siguiendo las indicaciones de la Dirección General de Instrucción Pública (I894) vinculan nuevamente al juego como parte de la gimnástica. Entre las características que deberían tener, se indican las siguientes: «I. Se elegirán los juegos que reporten mayor utilidad física, moral e intelectual. 2. Queda prohibido todo juego que ofrezca un peligro moral y físico. 3. Los juegos se adaptarán a la edad de los escolares y a las condiciones del local y la estación. 4. Para los ejercicios musculares debe escogerse un sitio al aire libre. $[\ldots]^{{ }^{19}}$. En una misma línea de interés es el que recoge la prensa a partir de la R. O. 3I de diciembre de I895, emitida por el Ministerio de Fomento en relación a la enseñanza de la gimnástica de los institutos, al referirse en su punto dos que «la enseñanza consistirá en ejercicios

\footnotetext{
${ }_{17}$ «Educación e Instrucción Primarias», La Asociación. Periódico Político Independiente, n. ${ }^{\text {I } 29}$, 9 de enero de i88I, p. I.

i8 Machado, A.: «Antonio Gianandrea», Revista El Museo Canario, 7 de abril de i88I, p. 8I.

19 «La enseñanza gimnástica», Diario de Las Palmas, 3 de abril de ı894, p. 2.
} 
dentro del aula, juegos al aire libre y excursiones [...]. Los juegos serán elegidos por los profesores con arreglo a los países donde ejerzan $»^{20}$. Además, estos juegos indicados exaltarán la tradición lúdica española frente a otras prácticas. Las propias orientaciones pedagógicas que se presentan en los congresos harán hincapié en «juegos genuinamente españoles» como los de pelota, el marro y los bolos, en detrimento del moderno sport, de influencia inglesa, como el crocket y el lawntennis ${ }^{21}$.

En otros casos, el juego se relaciona más con su función catártica y de gastos de excedente de energía que con su vinculación a la gimnasia. El maestro de escuela pública Bonet y Costa hace una interesante reflexión en torno a la infancia y el significado del juego en esas edades. En primer lugar, defiende el carácter de libertad del juego: «El niño que suele sentir los impulsos enérgicos de su libre albedrío, no consiente jamás se reglamenten sus expansiones y sus juegos; quiere que sean hijos de su temperamento, que se amolden a sus gustos y se armonicen con sus deseos ${ }^{22}$. En segundo lugar, el maestro se convierte en una figura de protección y orientación de las prácticas lúdicas que los jóvenes desarrollan espontáneamente y en libertad. Su intervención debe pasar casi desapercibida, ya que las iniciativas deben partir exclusivamente de los niños. El objetivo del juego, por tanto, es la diversión, el placer en el propio juego, sin ningún intelectualismo que atrofie la práctica natural de la infancia que juega. La propia actividad natural es beneficiosa para los niños y con ello se cubren muchos preceptos educativos, morales y espirituales. Finalmente, considera que los mejores juegos son los que ponen al organismo en movimiento utilizando como espacio el aire libre:

Persigamos en sus diversiones fines educativos que respondan a las necesidades de su vida física, intelectual y moral. Los juegos de los niños deben ser magníficos oasis en el desierto de la vida, donde se restauren y regeneren las abatidas fuerzas de su cuerpo y cobren nuevo vigor las facultades y energías del espíritu [...] Los juegos infantiles deben tener, pues, por primer objetivo, el desarrollo orgánico para que, repercutiendo en el alma, contribuya de una manera benéfica a los altísimos fines de la educación ${ }^{23}$.

Los juegos también tendrán cabida en las propuestas educativas de José Cabrera Díaz (I875-1939), representante de la Escuela Moderna en las Islas. Nacido en Santa Cruz de Tenerife, este periodista, líder sindical, defensor de la educación racionalista y de las escuelas populares, centrará algunos de sus artículos educativos en la importancia y los objetivos del juego como parte de la educación integral del ser humano. Este discurso hay que entenderlo en el origen de su pensamiento pedagógico, definido por un posicionamiento crítico a la enseñanza estructurada por las instituciones públicas, en el que lo dogmático prevalecía sobre lo científico. En esta misma línea argumental, defiende el discurso de la

«La enseñanza gimnástica en los institutos», Diario de Las Palmas, 3I de enero de I895, p. 2.

«Del Congreso de Higiene», Diario de Tenerife, 30 de mayo de i898, p. 2.

«Lo que deben ser los juegos de los niños», La Región Canaria, I2 de julio de I9oo, p. 2.

Ibídem. 
ciencia, basado en la observación y la experiencia, como base para el cambio en la enseñanza popular, racional y libre ${ }^{24}$. Esta idea de libertad es uno de los pilares en los que defiende la práctica del juego en el desarrollo educativo de la infancia. El juego aparece como algo natural tanto en el ámbito escolar como fuera de él. En sus pensamientos, si la ciudad está diseñada con espacios para el juego infantil, los niños se alejarán de los vicios y tendrán una vida saludable. Frente a la cantidad de ejercicio físico promovido por la gimnasia, el juego además aportaría calidad, sustentada en el placer del propio juego:

A los niños les es indispensable el juego, sobre todo por lo que respecta a su constitución, a su salud y a su desarrollo físico. Erróneamente pretendiendo responder a una corriente bien acentuada de la pedagogía moderna, se han establecido gimnasios en los institutos y en las escuelas elementales. Mas eso no es suficiente: podríamos asegurar que no es lo que se pide. Con los gimnasios solo es tenida en cuenta la cantidad y no la cantidad y la calidad de desarrollo físico que los juegos producen ${ }^{25}$.

Siguiendo las experiencias de Spencer, y la de muchas escuelas norteamericanas, belgas y suizas del momento, defiende que el estado placentero que siente el niño cuando juega es la clave para su desarrollo físico e intelectual; de ahí la defensa imperiosa que hace de incorporar los juegos en el aula. Recupera, igualmente, la tradición pedagógica de llevar al niño a la naturaleza, utilizando el juego como el mejor método de aprendizaje a través de los sentidos ${ }^{26}$. Junto a los juegos, y en consonancia con el aprendizaje a través de la experiencia y de los sentidos, justifica la necesidad de la educación racional, base de su pensamiento pedagógico:

La educación racional será, pues, la que conserve al hombre la facultad de querer pensar, de idealizar, la que esté basada únicamente sobre las necesidades naturales de la vida; la que deje manifestarse libremente esas necesidades que facilite lo más posible del desarrollo y la efectividad de las fuerzas del organismo para que todas se concentren sobre un mismo objetivo exterior: la lucha por el trabajo para el cumplimento que reclama el pensamiento. Se renovarán, pues, por completo las bases de la educación actual: en lugar de fundar todo sobre la instrucción teórica, sobre la adquisición de conocimientos que no tienen significación para el niño, se partirá de la instrucción práctica, aquella cuyo objeto se le muestre claramente, es decir, se comenzará por la enseñanza del trabajo manual ${ }^{27}$.

Años más tarde, Cabrera Díaz recurriría en su discurso al juego para contraponer la escuela tradicional con la escuela nueva. Una escuela tradicional que

${ }^{24}$ Ferraz, M.: «Las propuestas educativas libertarias de José Cabrera Díaz», Historia de la Educación, I7 (1998), pp. 33I-347.

25 «Higiene. El juego y los niños», El Tiempo, n. ${ }^{\circ}$ II 77,2 de marzo de 1907, p. I.

${ }^{26}$ «Notas pedagógicas. El juego educativo», El Tiempo, n. ${ }^{\circ}$ 1337, 6 de septiembre de 1907, p. I.

${ }_{27}$ «Notas y observaciones. Trabajos manuales», El Tiempo, n. ${ }^{\circ}$ 1394, I2 de noviembre de 1907, p. I. 
en la España de aquellos años todavía seguía anclada en métodos y programas alejados de las grandes corrientes de pensamiento europeo, y la que, solo a través de espacios críticos al sistema imperante, encontraba hueco en una minoría social. La educación en la naturaleza, al aire libre y en extensos campos de juego se convierte en la receta ideal para establecer en los centros escolares de Canarias:

Esa escuela clásica ya ha desaparecido en los países civilizados; pero desgraciadamente es la que todavía en España educa y moldea las nacientes generaciones. La escuela, según el concepto pedagógico moderno, debe ser para desarrollar e instruir al niño por medio de lecciones de cosas, al aire libre, en extensos campos de juego, en contacto directo y constante con la naturaleza ${ }^{28}$.

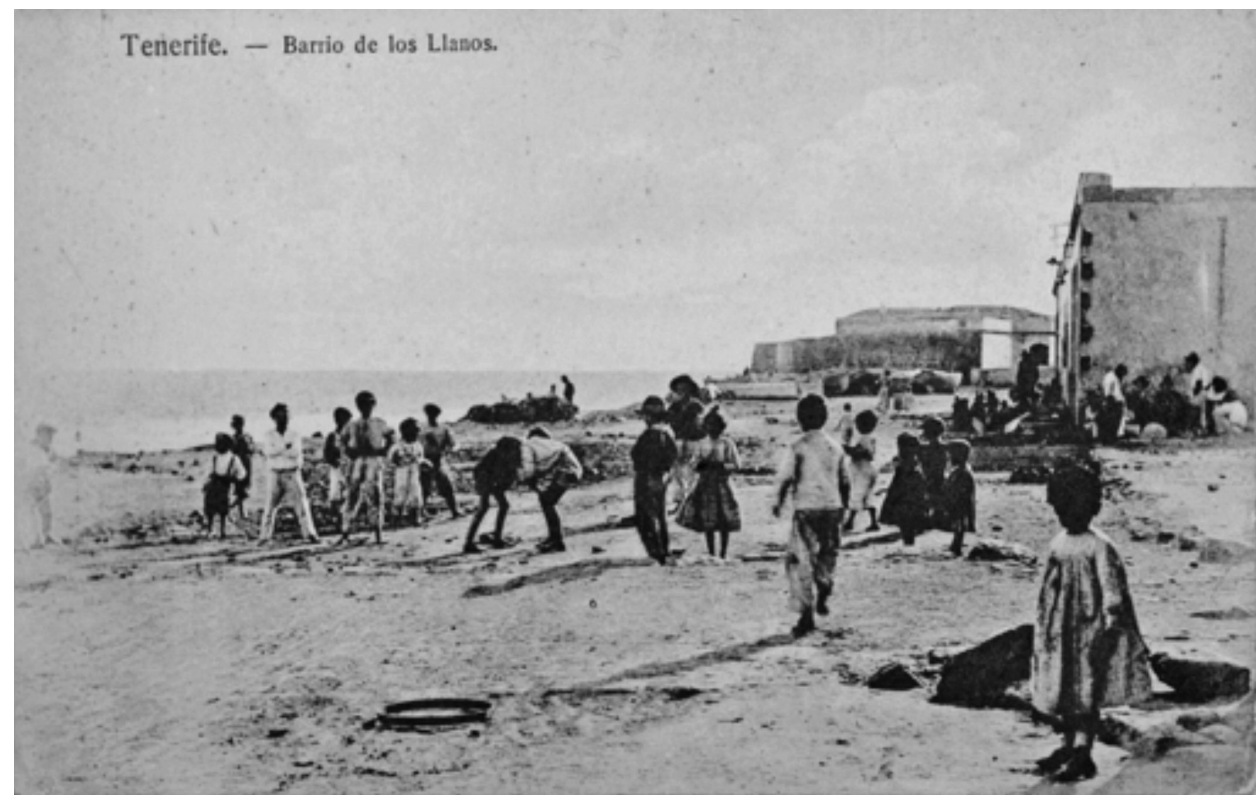

Imagen i: Niños jugando a la lucha canaria en Santa Cruz de Tenerife (c. 1900). Archivo: Colección Ulises S. Castro Núñez.

\section{La prensa pedagógica en la difusión del juego: del periodo primorriverista a la II República}

Si hasta ahora hemos analizado algunos ejemplos de cómo el juego y su función educativa se incorpora en la prensa periódica en las Islas, otra de las fuentes para su estudio es propiamente la prensa pedagógica. Este medio de comunicación no solamente fue un espacio donde se debatían intereses políticos o educativos; también ha sido un elemento promotor y generador de críticas o denuncias

28 «El juego en la cultura física», El Tiempo, n. ${ }^{\circ}$ 3203, 28 de octubre de r9ı, p. I. 
LOS JUEGOS TRADICIONALES Y LA EDUCACIÓN EN CANARIAS: DE LAS PROPUESTAS

DEL SIGLO XIX A LAS REGULACIONES AUTONÓMICAS

ANTONIO S. ALMEIDA AGUIAR Y ULISES S. CASTRO NÚÑEZ

de la situación y desempeño de los maestros. La preocupación por la formación docente a través de la prensa pedagógica fue una denuncia constante en las Islas; se trataba de uno de los pocos canales eficientes para lograr hacer llegar a los maestros las propuestas educativas del Gobierno, los ideales educativos de la patria y los avances que en educación se estaban planteando en otros países europeos. A la prensa pedagógica en Canarias no solo se le había otorgado una responsabilidad educadora para aminorar la ignorancia del pueblo, sino que también tuvo un papel importante como agente alfabetizador de la población más pobre y aislada, y una relevante contribución a la formación de los maestros difundiendo las ideas más progresistas de la época, además de defender los intereses generales del profesorado y denunciar su precaria situación económica, social y profesional ${ }^{29}$. Entre los rotativos más importantes de las Islas, tanto por su posicionamiento ideológico como por su duración temporal, merecemos destacar el Eco del Magisterio Canario ${ }^{30}$. En sus páginas, los juegos y su relación con la educación ocuparán algunas editoriales.

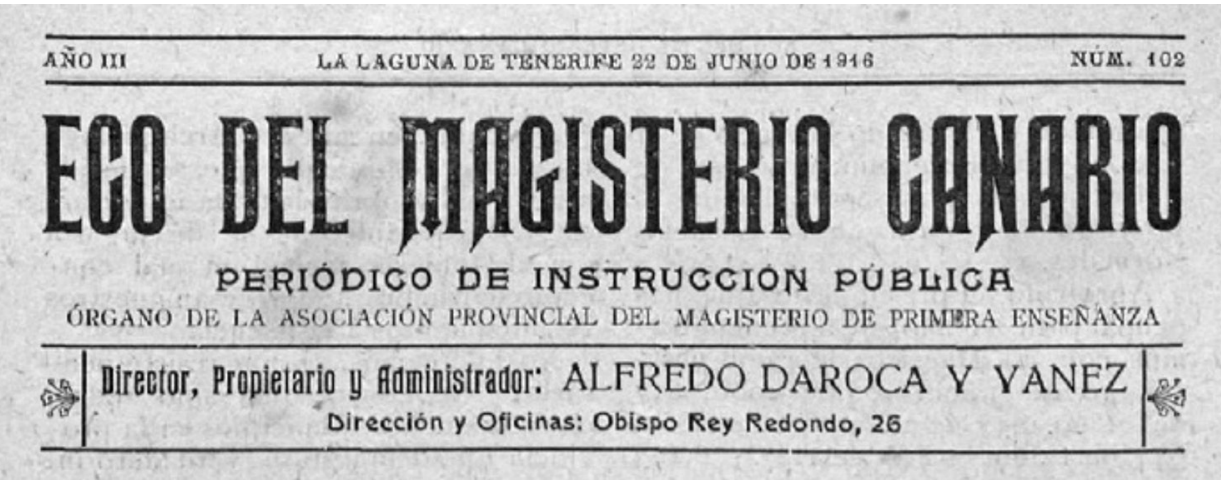

Imagen 2: Cabecera del Eco del Magisterio Canario, 22 de junio de i9i6.

Archivo: Jable. Archivo Prensa Digital. Universidad de Las Palmas de Gran Canaria.

Ya hemos visto como, en ocasiones, encontramos relaciones directas entre el juego y la gimnasia, pero también aquellos que oponen el juego a la gimnasia, al ser esta considerada como la principal actividad de la educación física. Maximiliano Benítez, maestro de primera enseñanza en el pueblo de Garafía (La Palma), defiende una educación integral como base para la de la sociedad. Esa educación se basaría en dos puntos principales: la escuela y la educación física. Entre los contenidos de la educación física, partiendo de la naturaleza de la infancia, así como de sus condiciones higiénicas y pedagógicas, se encuentran el canto, el juego, los paseos, las excursiones, las colonias escolares, etc. En este contexto, el maestro

29 Negrín, J.: « La prensa especializada de enseñanza primaria en Canarias durante la segunda mitad del siglo XIX», Historia de la Educación, 2 (1983), pp. 307-315.

3o Ferraz, M.: «Regeneracionismo educativo y corporativismo docente. Análisis de contenido de Eco del Magisterio Canario (1914-1940)», Anuario de Estudios Atlánticos, 44 (1998), pp. 493-555. 
canta, juega y pasea con el alumnado acercando la escuela a la realidad infantil a través de las actividades lúdicas: «[...] el maestro se ha convencido de su valor pedagógico, y considerando al niño factor activo y el más importante en la obra de la enseñanza, acude al recurso de hacer manual juegos corporales que contribuyan a la integridad de la educación $»^{31}$. Aunque menos frecuente en las reflexiones que estamos viendo, las maestras también analizaron el juego para entender mejor la infancia y su posterior desarrollo; son los casos de María González Rodríguez y Candelaria Cáceres. La primera de ellas analiza el juego de los niños siguiendo el pensamiento de Montaigne, en el que el juego se convierte en su única ocupación y, por lo tanto, una de sus primeras actividades. El juego, de esta manera, trasluce las necesidades del ser humano de experimentar a consecuencia del desarrollo corporal y del espíritu. María González se detiene a realizar una sencilla clasificación por la edad del niño y el tipo de juego, desde los básicos por imitación a aquellos en los que ya se introducen las normas:

En la primera edad los juegos son todos de imaginación e imitación; juegan a torero, soldado, etc.; más tarde, a medida que la inteligencia se va desarrollando se van cansando de la falta de finalidad de esos juegos y adquieren otros que satisfagan a las nuevas necesidades espirituales; entonces surgen los juegos sometidos a ciertas leyes y cuya realización constituye un triunfo, digno de ser alcanzado con habilidad y esfuerzo ${ }^{32}$.

Además de Montaigne, se hace eco de los Jardines de Infancia de Froebel y su metodología basada en el juego. Esta misma organización de la enseñanza, sustentada en la libertad de acción del educando a través del juego, lleva a otro de los pedagogos más relevantes del archipiélago, Baltasar Champsaur Sicilia (1856-1934), a reflexionar sobre el mismo. El método integrado, del que sin duda Champsaur es deudor, se fundamenta en la actividad y la acción, una de sus aportaciones más valiosas. Considera al niño un sujeto creador que lleva dentro el germen y la capacidad de la actividad espontánea y productiva, y crea su pedagogía lúdica para intentar despertar en él las facultades mediante estímulos, respetando siempre su libre desarrollo. Como la educación del párvulo se deriva de las necesidades y tendencias espontáneas, se debe permitir el libre desarrollo de lo genuino y singular que en él se encuentra con la máxima libertad, «tales son los verdaderos resultados de la acción libre de las energías intelectuales y morales laicas, cuyo fin es forjar hombres fuertes de cuerpo y espíritu, de personalidad libre e independiente, cuyos actos han de ser completamente suyos [...]»33. Por su parte, la maestra Candelaria Cáceres recurre a la metodología de Montessori para analizar la adquisición de conocimientos del niño a través de los juegos infantiles ${ }^{34}$. Otras editoriales seguirán estudiando las

«La escuela y la educación física», Eco del Magisterio Canario, 30 de enero de 1919, pp. 3-4.

«Qué es el niño», Eco del Magisterio Canario, n. ${ }^{\circ}$ 476, 22 de febrero de 1924, pp. I-4.

33 Champsaur, B.: La escuela laica, Las Palmas, Ed. Tip. y Lib. High-Life, 1930, p. 9.

34 «La lectura según María Montessori», Eco del Magisterio Canario, is de octubre de 1925, pp. 4-5. 
LOS JUEGOS TRADICIONALES Y LA EDUCACIÓN EN CANARIAS: DE LAS PROPUESTAS

DEL SIGLO XIX A LAS REGULACIONES AUTONÓMICAS

ANTONIO S. ALMEIDA AGUIAR Y ULISES S. CASTRO NÚÑEZ

posibilidades del juego en la educación. En la mayoría de los textos estudiados, es una constante la referencia a trabajos de pedagogos extranjeros, además de los ya mencionados, como son Durot, Claparède, Jentzer, Spencer, Hutchinson, etc. En sus contenidos, coinciden en situar al juego como base para la educación física de la infancia y su posterior desarrollo como adulto ${ }^{35}$. La defensa del juego desde la perspectiva pedagógica también lleva aparejada la necesidad de nuevos espacios en la escuela para su puesta en práctica, como ya mencionamos en el pensamiento de Cabrera Díaz. De ahí que muchos autores reivindiquen esta circunstancia, sobre todo para la práctica de algunos juegos tradicionales, así como otros importados:

Aquí los niños juegan al football o balompié; sólo el juego de la pelota en Lanzarote y Fuerteventura se parece al de las Vascongadas; y nuestros niños para jugar al fútbol y a la lucha canaria, necesitan de pequeños campos de recreo situados en cada barrio y anejos a grupos escolares en donde reciben la enseñanza elemental del que carecen ${ }^{36}$.

El maestro Mencia Roy recogía las palabras de Cossío para defender la presencia de espacios para el juego: «Escuela no ya sin patio, ni sin raquítico jardín, que ni aún para alegrar la vida de los transeúntes sirve, sino sin campo escolar, sin campo de juego, no es escuela sana» ${ }^{37}$. Y cuando no existía esta posibilidad, los maestros más progresistas salían con los niños en excursiones u organizaban colonias escolares para dar cabida al juego. Las primeras colonias escolares organizadas en Canarias (1922) tienen en el pueblo de Teror, en la isla de Gran Canaria, su punto de partida. Sus principales valedores, como Sergio Calvo, Baltasar Champsaur o Cristóbal González, conocían la relevancia de la educación en la naturaleza y entendían el juego como aprendizaje, al cumplir dos variables: el desarrollo de las habilidades y el proceso de enculturación. La primera de ellas se justifica al adquirir los niños y las niñas las habilidades necesarias para adaptarse al medio, como ocurre con las habilidades cognitivas, afectivas y sociales. A la vez sirven para ir, progresivamente, asimilando la propia cultura. Por otro lado, a través del juego aprendemos nuestra propia cultura. De esta manera, podemos encontrar símbolos, valores, conceptos o ideas que están más o menos enmascarados en nuestras actuaciones diarias. En el juego se aprenden, sin planteárnoslo como objetivo de su práctica, el lenguaje, los gestos, los valores que encierran normas, los tipos de espacios y tiempos culturales, los roles y su relevancia. Entre los juegos infantiles que los niños y niñas practicaron en las colonias escolares estaban la santorra, el corito de san Miguel, el corro de la patata, juegos de pelota,

35 «De educación física», Eco del Magisterio Canario, 7 de abril de I927, pp. 4-6; «Algo sobre educación física», Eco del Magisterio Canario, 7 de octubre de 1927, pp. 3-5; «Por el juego se inicia el niño en el trabajo", Eco del Magisterio Canario, 7 de septiembre de 1927, pp. 3-5.

${ }_{36}$ «Lugares para juegos infantiles y grupos escolares», Diario de LasPalmas, 3I de enero de I928, p. I.

37 «Campos de juego», El Campo. Periódico del Arbolado y del Progreso del País, n. ${ }^{\circ}$ 57-58, i de enero de 1929, pp. 20-23. 
LOS JUEGOS TRADICIONALES Y LA EDUCACIÓN EN CANARIAS: DE LAS PROPUESTAS

DEL SIGLO XIX A LAS REGULACIONES AUTONÓMICAS

ANTONIO S. ALMEIDA AGUIAR Y ULISES S. CASTRO NÚÑEZ

etc. Junto a los juegos infantiles, los colonos practicaron el juego tradicional por excelencia del archipiélago: la lucha canaria ${ }^{38}$.

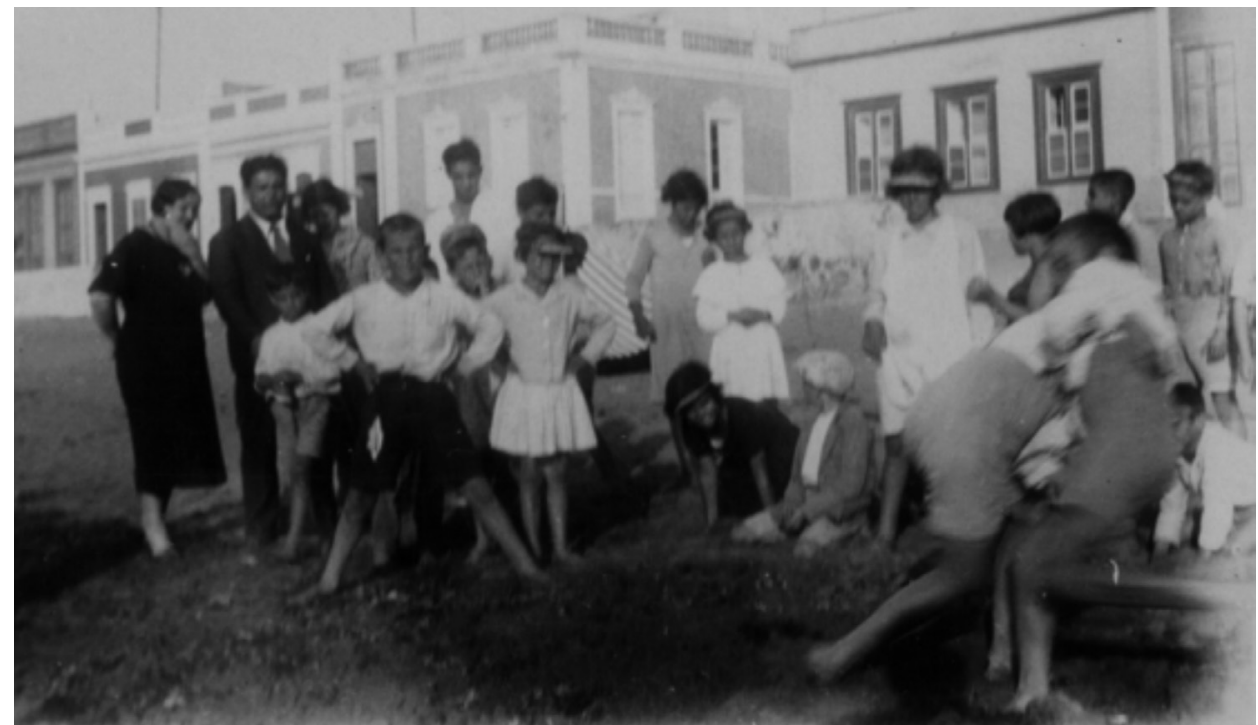

IMAgEN 3: Niños jugando a la lucha canaria durante la Colonia Escolar de la Playa de Las Canteras (Las Palmas de Gran Canaria, 1933).

Archivo: Colección Ezequiel Guerra de la Torre.

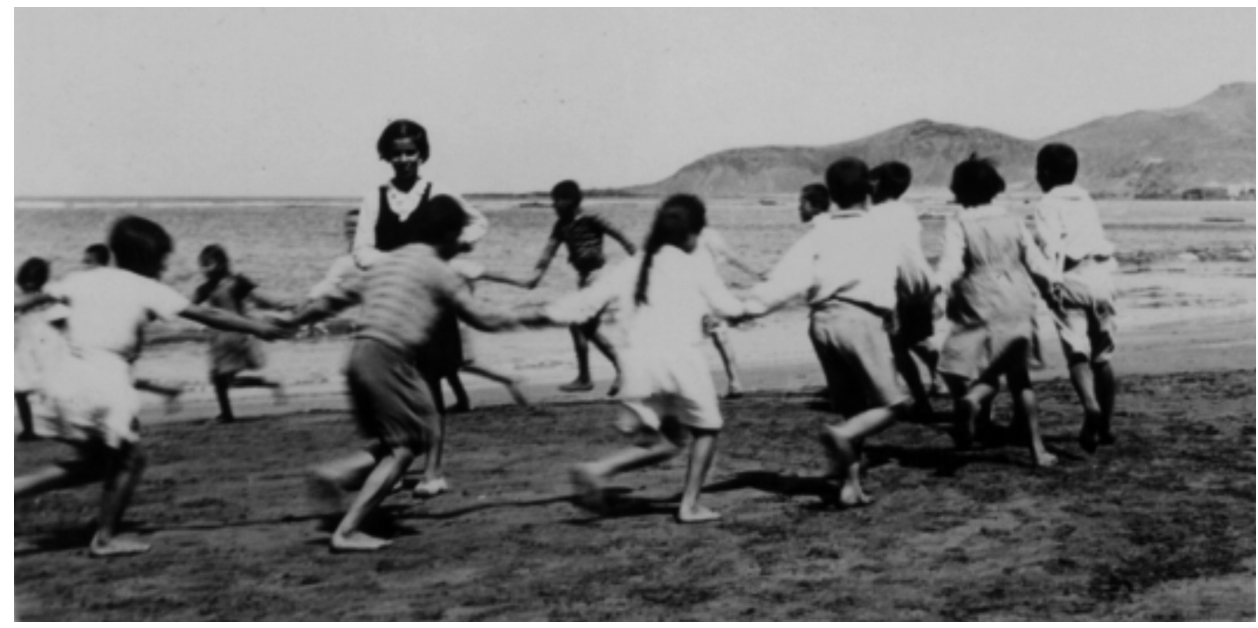

Imagen 4: Niños jugando a el corito de San Miguel durante la Colonia Escolar en la Playa de Las Canteras (Las Palmas de Gran Canaria, 1933).

Archivo: Colección Ezequiel Guerra de la Torre.

38 Almeida, A.: Las colonias escolares en Gran Canaria (1922-1936). Textos e imágenes para su estudio, Madrid, Mercurio, 2018. 
LOS JUEGOS TRADICIONALES Y LA EDUCACIÓN EN CANARIAS: DE LAS PROPUESTAS

DEL SIGLO XIX A LAS REGULACIONES AUTONÓMICAS

ANTONIO S. ALMEIDA AGUIAR Y ULISES S. CASTRO NÚÑEZ

Desde el ámbito castrense, el comandante de Infantería Emilio Ferrer Valdivielso (1877-I937) puede ser considerado como uno de los mayores defensores de la educación física en el archipiélago durante el primer tercio del siglo pasado. El interés por la educación como base para el desarrollo del hombre le lleva a escribir la obra Un problema nacional (I9II), siendo la educación el eje central en torno al que gira el texto. Premiada en el Ateneo de La Laguna (Tenerife) el is de septiembre de igıo, al año siguiente sería publicada en Toledo por la imprenta del Colegio de María Cristina para Huérfanos Desamparados. Estructura la obra en varios capítulos, siendo los de mayor interés los que analizan los distintos ámbitos de la educación. De esta manera, centra su atención en la educación higiénica, la educación física, la educación moral, la educación patriótica, la educación estética, la educación agrícola, la educación intelectual y la educación de los sentidos $^{39}$. En relación a este último aspecto, en uno de sus numerosos artículos de prensa, reflexiona sobre la necesidad de la práctica del ejercicio corporal en la infancia, para lo que propone la creación del Kindergarten de Froebel (Jardín de Infancia). En esta escuela, niños de 5 a io años, organizados con un maestro en grupos no superiores a treinta alumnos, desarrollarían su educación, entre otras actividades, a través de juegos infantiles, disponiendo para ello de un espacio en el «que sus músculos se estiren y sus pulmones dilaten al aire libre con los juegos y carreras, gritos y canciones infantiles». Ferrer, fundador del escultismo en las

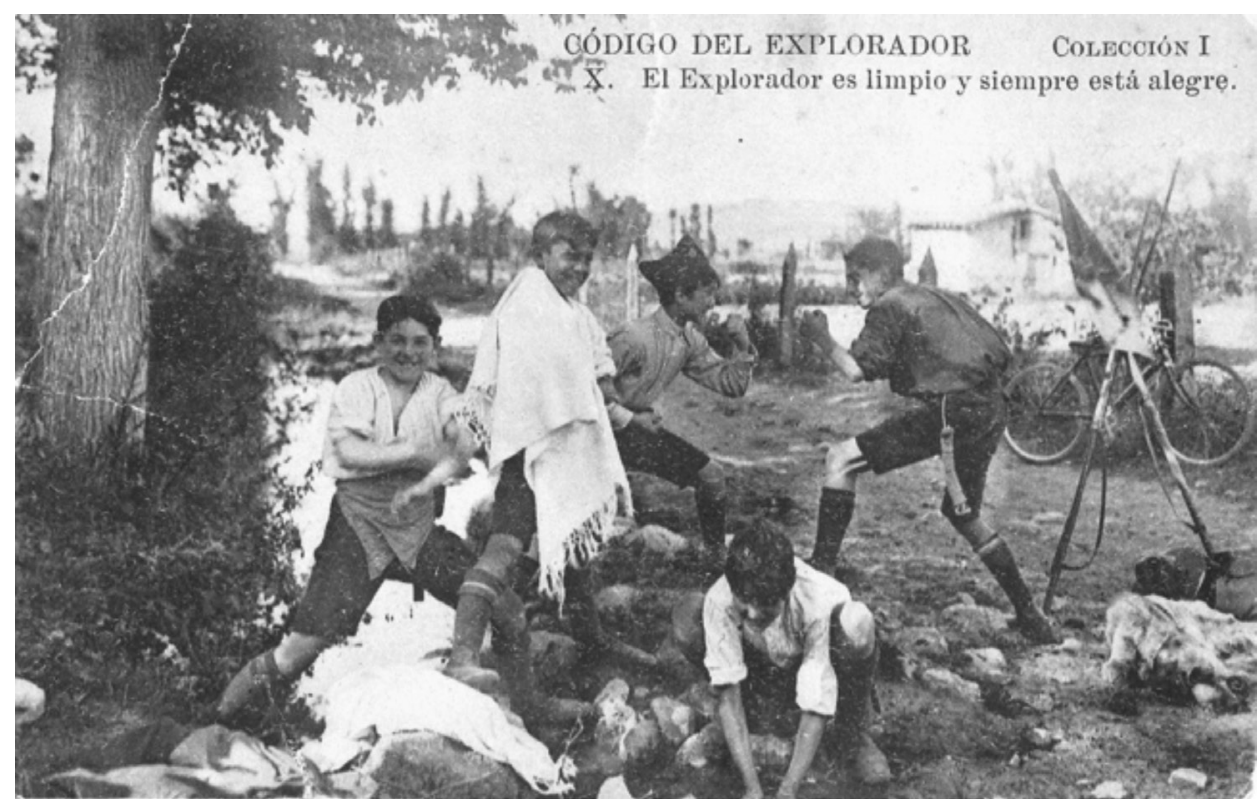

IMAGEN 5: Juegos y entretenimientos de campamento scout (primer tercio siglo xx). Archivo: Colección Guillermo Rodríguez Padrón.

39 Almeida, A.: Infancia y educación Física en Canarias. Estudios históricos, Las Palmas de Gran Canaria, Cabildo de Gran Canaria-Consejería de Deportes, 2006. 
Islas Canarias ${ }^{40}$, también hace suyas las palabras del pedagogo agustino Teodoro Rodríguez: «La educación ha de tender a formar seres robustos y vigorosos en el cuerpo, en la inteligencia y en el corazón», y establece tres núcleos fundamentales en la Educación: Educación física, «Toda la fuerza y toda la inteligencia de una raza dependen de la salud y desarrollo físico del niño»; Educación moral, «el fundamento de la fe, cristiana y de todo buen vivir está en que los hombres, desde niños, afiancen las rectas y buenas intenciones»; y la Educación intelectual, «la inteligencia no es un vaso que hay que llenar, sino un faro que hay que encender (Plutarco)» $»^{41}$. De esta manera, desde el ámbito militar, también surgen propuestas en torno al juego educativo.

\section{La visión del juego tradicional desde la ideología franquista}

El juego motor, en general, y el juego tradicional, en particular, constituyen un recurso fundamental en el desarrollo físico, moral e intelectual del ser humano en las primeras etapas de su formación. Así lo pusieron de relevancia los antecedentes que hemos analizado con anterioridad. La llegada del franquismo a las administraciones del Estado y a las instituciones educativas nos ratifica el conocimiento que los dirigentes políticos han tenido de ese hecho; el juego, la actividad y el deporte han sido utilizados como vehículos de propaganda ideológica, control y alienación de la población o fines higiénico-militares, en distintos momentos de la historia. Podemos observar como la Inspección Provincial de Primera Enseñanza, en septiembre de 1936, y de cara a inicio del nuevo curso escolar, transmite una serie de instrucciones que emanan de la Junta de Defensa Nacional: «Los alcaldes y delegados que éstos designen cuidarán: [...] B) - De que los juegos infantiles obligatorios, tiendan a la exaltación del patriotismo sano y entusiasta de la España Nueva» ${ }^{42}$.

El Sindicato Español de Magisterio (SEM), que agrupaba a los educadores de enseñanza de infancia, primaria y media, así como al Cuerpo de Inspectores, promovió la realización de seminarios de formación y especialización de los docentes, además de las «Semanas pedagógicas», que realizaban por todas las provincias con colaboración de catedráticos, profesores, artistas, poetas, etc. ${ }^{43}$; en un artículo publicado en el periódico Falange, titulado "Caracterología de la Escuela Moderna», sigue la misma línea comentada en el párrafo anterior, pues recoge lo siguiente:

40 Almeida, A.: «Escultismo y Educación Física en Canarias», Vegueta. Anuario de la Facultad de Geografía e Historia, 8, Servicio de Publicaciones de la Universidad de Las Palmas de Gran Canaria (2004), pp. 5I-69.

${ }_{41}$ Ferrer, E.: «Laboremus. Por la patria y por la raza», La Provincia, n. ${ }^{\circ}$ 7997, 24 de octubre de I93I, p. 3.

${ }_{42}$ «Inspección Provincial de Primera Enseñanza», Diario de Las Palmas, n. ${ }^{\circ}$ I4798, 30 de septiembre de I936, p. IV.

43 Rodríguez López, S.: La Sección Femenina y la sociedad almeriense durante el Franquismo. De las mujeres del Movimiento al Movimiento Democrático de Mujeres, tesis doctoral. Universidad de Almería, 2004, pp. 596-597. 
LOS JUEGOS TRADICIONALES Y LA EDUCACIÓN EN CANARIAS: DE LAS PROPUESTAS

DEL SIGLO XIX A LAS REGULACIONES AUTONÓMICAS

ANTONIO S. ALMEIDA AGUIAR Y ULISES S. CASTRO NÚÑEZ

Debe imprimirse a los juegos infantiles un sello de combatividad de acuerdo con la fortaleza física y el espíritu de sacrificio que ha de adquirir la infancia. Pero, sobre todo, ha de realizarse en ésta una implacable sementera de disciplina. La disciplina es la virtud que más alta ha de cotizarse ahora en la escuela española. [...] En resumen: más que suministrar cultura hueca, pedante y universalista, la escuela española -para decirlo con una frase exacta- debe a nuestro juicio, robustecer el GENIO HISPANO ${ }^{44}$.

La búsqueda y la revalorización de «lo nacional», en relación a los juegos tradicionales, se resalta en la publicación en la prensa de Canarias de una circular del jefe del Servicio Nacional de Primera Enseñanza, Romualdo de Toledo y Robles, de fecha 5 de marzo de 1938 , en la que se dan instrucciones sobre las orientaciones que deben tener las distintas materias del currículo para este nivel educativo. Respecto a la Educación Física se expresa lo siguiente:

Hasta que un Estatuto especial regule la educación física nacional, se considera indispensable intensificar la educación física en la Escuela. Pero es preciso advertir que la educación física no es el deporte que, sin empleo científico apropiado, hasta después de la pubertad resulta casi siempre pernicioso; ni es tampoco el desarrollo del músculo con aparatos.

Tómese como base constantemente los juegos infantiles de la localidad, ennobleciéndolos y restaurándolos. En vez del exotismo en los juegos, busquemos en ellos las puras corrientes nacionales, los juegos de pelota, los bolos, la comba, el marro, etc., etc., tan españoles, deben utilizarse lo mismo que los de imitación, corros, marchas cantadas, carreras, saltos, etc. Que jueguen los niños en los recreos, pero siempre bajo la cuidadosa dirección del Maestro ${ }^{45}$.

La lectura de la circular posibilita conocer algunos de los juegos tradicionales propuestos para su inclusión en las clases de Educación Física, sin diferenciar entre juegos infantiles y de adultos; imaginamos que tantos los de pelota como los de bolos, con amplia difusión por toda España en esa época, tanto en las áreas rurales como urbanas, que son juegos prioritariamente de adultos, tendrían que ser sometidos a adaptaciones para su aplicación en el entorno escolar. Por otro lado, es de gran interés observar como desde una administración nacional se promueve la práctica de los juegos en el entorno, de los juegos tradicionales infantiles, adelantándose en el tiempo a alguna de las pretensiones de los currículos de Educación Física de la etapa autonómica de la democracia en nuestro país.

Las indicaciones respecto a que esos juegos infantiles deben ennoblecerse y restaurarse, nos hace pensar que en esos momentos podían ser considerados como algo de poca importancia, liviano, y que estaban en una fase de decaimiento o desaparición. El traslado de un importante contingente de población desde

44 Fernández Rodríguez, A.: "Caracterología de la Escuela moderna», Falange, n. ${ }^{\circ} 298,25$ de noviembre de 1937, p. 2.

45 «Por la Jefatura del Servicio Nacional de Primera Enseñanza ha sido dirigida la siguiente circular a la Inspección de Primera Enseñanza y maestros nacionales, municipales y privados de la España Nacional», Gaceta de Tenerife, n. ${ }^{\circ}$ 9067, i8 de marzo de 1938, p. 3. 
las áreas rurales hacia las zonas urbanas influyó de manera determinante porque supuso cambios profundos en el contexto sociocultural, espacial y material que sostenía la práctica tradicional de estos juegos; al tiempo que, quizás, en las áreas urbanas competían con otras actividades como podía ser el deporte. Otros aspectos que no podemos dejar pasar por alto es que existe un enfrentamiento entre deporte y juego, para la etapa de la infancia, en la que se promueve y sale victorioso el juego, quizás por el carácter natural y más atractivo que tiene el juego frente al deporte; y la identificación de un tiempo lúdico, fuera de lo curricular, los recreos, donde también estará presente la orientación del docente.

La idea de revalorizar los juegos tradicionales, que en algunos casos habían caído en el olvido o habían perdido su lugar como forma de ocupar el tiempo de ocio en beneficio de otras actividades como el fútbol, sigue vigente algunos años después:

En España tenemos una gran riqueza y variedad de juegos y, sin embargo, nos parece que los hermosos juegos tradicionales están un poco olvidados; han sido casi totalmente suplantados por el fútbol. Cuando observamos a los niños de una Escuela en el momento del recreo, nos causa pena ver que su actividad lúdica parece haber quedado, reducida a dar patadas a una pelota de trapo.

Es preciso restaurar los juegos tradicionales españoles. Sería tarea digna del Magisterio de España ir recopilando los juegos de las distintas regiones españolas.

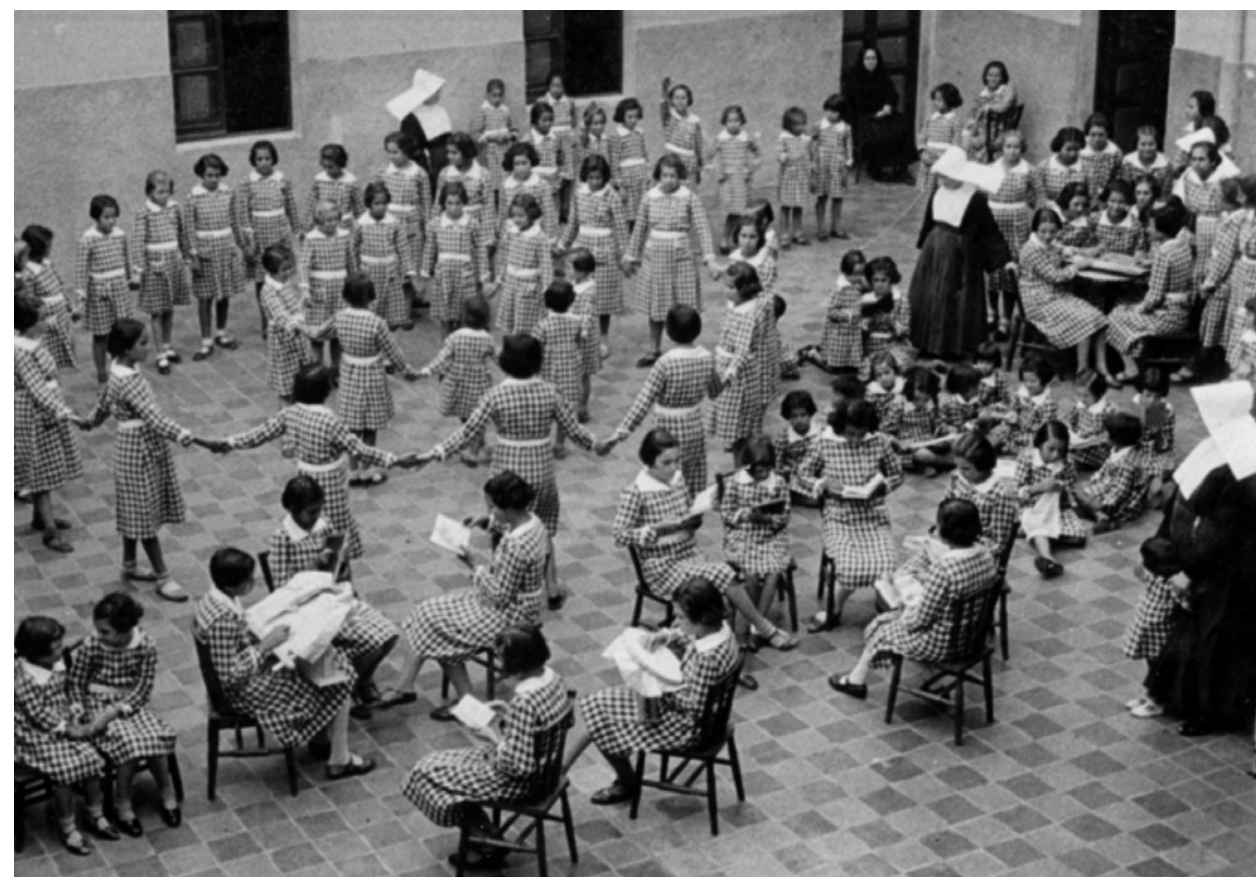

IMAgEN 6: Niñas jugando y haciendo labores manuales en el patio del colegio Nuestra Señora de los Ángeles (1940-1950). Archivo: Fotografía histórica de Canarias. FEDAc/Cabildo de Gran Canaria. 
LOS JUEGOS TRADICIONALES Y LA EDUCACIÓN EN CANARIAS: DE LAS PROPUESTAS

DEL SIGLO XIX A LAS REGULACIONES AUTONÓMICAS

ANTONIO S. ALMEIDA AGUIAR Y ULISES S. CASTRO NÚÑEZ

Brindamos la idea a los Maestros y les invitamos a que recojan los de la localidad donde ejerzan ${ }^{46}$.

La propuesta a los maestros de recoger los juegos tradicionales infantiles en las localidades donde ejercían su docencia ya fue materializada en Tenerife, unos años antes, por Luis Diego Cuscoy (1907-1987). Este maestro publica en I943 la obra Tradiciones Populares II: Folklore infantil47, con el material etnográfico recogido durante su ejercicio como profesor en El Sauzal y Cabo Blanco, principalmente en la primera de las escuelas mencionadas (donde ejerció desde septiembre de 1933), pues en el sur de la isla de Tenerife solo estuvo algo más de un año y cuatro meses, desde su traslado forzoso el i de septiembre de 1940 en un expediente de depuración motivado por la denuncia de otro maestro del colegio de El Sauzal «por no dar clase de religión a los niños» ${ }^{4}$. Este trabajo etnográfico de Cuscoy está influenciado por los contactos que tuvo con el folclorista gallego Bouza-Brey durante su estancia en Lugo en el periodo I93I-I933, al ser este su primer destino docente. En esta misma línea, el capítulo que dedica María Rosa Alonso (1909-20II) a los juegos de su infancia, en la obra Un rincón tinerfeño. La Punta del Hidalgo ${ }^{49}$, constituye otro magnífico documento sobre el catálogo lúdico tradicional infantil de la isla de Tenerife, en las primeras décadas del siglo xx.

Los juegos tradicionales infantiles también están presentes en la escuela en otros contextos en los que se pretende visibilizar la importancia para la educación del complemento entre la familia y el maestro mediante la realización de actividades en las que participen ambos:

Para mejor estímulo de esta labor social educativa puede buscarse un buen motivo o pretexto en la organización de exposiciones escolares, de trabajos manuales, juegos infantiles, coros folklóricos, equipos gimnásticos y deportivos, etc., en cuyas exhibiciones estén presentes los familiares de los chicos y participen con sus Maestros de la íntima satisfacción de ver desarrollarse una inteligencia fecunda y un cuerpo $\operatorname{sano}^{50}$.

La defensa de las prácticas lúdicas tradicionales como elemento educativo también se hace explícita con el más popular y difundido de los deportes tradicionales de Canarias, la lucha canaria. Además, su incorporación como contenido curricular o como actividad extraescolar se propone como una de las vías

${ }^{46}$ «Educación Física. Juegos Infantiles», Escuela Azul, Santa Cruz de Tenerife, n. ${ }^{\circ}$ 273, ro de octubre de 1946 , p. 8.

47 Diego Cuscoy, L.: Tradiciones Populares II: Folklore infantil, La Laguna de Tenerife, Instituto de Estudios Canarios, 1943.

${ }_{48}$ Mederos, A. y Escribano, G.: Julio Martínez Santa-Olalla, Luis Diego Cuscoy y la Comisaría Provincial de Excavaciones Arqueológicas de Canarias Occidentales (I939-I955). Sevilla, Museo Arqueológico de Tenerife, 20II. p. 239

49 Alonso, M. R.: Un rincón tinerfeño. La Punta del Hidalgo, La Laguna, Real Sociedad Económica de Amigos del País de Tenerife, 1944.

so Hernández de la Rosa, E.: "Colaboración social con el Maestro», Escuela Azul, Santa Cruz de Tenerife, n. ${ }^{\circ}$ 408, io de agosto de I950, p. 8. 
para mantener su práctica y promocionarla. Con el apoyo del Cabildo Insular de Gran Canaria (1952), la Federación Regional de Lucha Canaria promueve una competición interescolar a la que están invitados todos los colegios de la isla; los escolares serían adiestrados por las «figuras más destacadas» de este deporte y la competición se desarrollaría en el Estadio Insular, poniéndose en juego una copa que sería ganada por el colegio vencedor ${ }^{\text {sI. }}$ Un dato significativo es que serán luchadores de prestigio, sin ninguna formación pedagógica adicional, los que se van a ocupar de enseñar a luchar a los niños, y no los maestros.

La competición interescolar se desarrolló en los meses siguientes: «En las tardes en que hemos asistido al Estadio Insular para ver a los jóvenes, a esa nueva generación que mide sus fuerzas con amor propio y con coraje, casi sin recompensa alguna, veíamos renacer las esperanzas firmes del resurgimiento de la lucha canaria» $\aleph^{2}$. El autor del artículo otra vez vuelve a incidir sobre la importancia de introducir la lucha canaria en la escuela, como un contenido más de los que allí se imparten: «Es una bella práctica que debía ser recomendada en todos los centros escolares, como un entretenimiento, como una parte más de la clase. Vale la pena pensar en no dejarla morir» ${ }^{33}$.

Los valores educativos de la lucha canaria se vinculan al desarrollo de los patrones motores, el respeto a las reglas que regulan el transcurso del enfrentamiento, el avance moral y a la ocupación del tiempo ocioso en unas edades en las que puede ser peligroso para el niño o el joven; pero también a la realización de una actividad que es tradicional del territorio canario, que forma parte de su cultura y que mantiene el vínculo con las prácticas físicas que realizaban los indígenas preeuropeos.

Siempre hemos creído que la importación y práctica de los deportes debe tener por base, el que sea típico de cada región. [...] notamos la omisión de equipos de lucha canaria entre las realizaciones deportivas de nuestros estudiantes. Es una lástima y un error; una lástima porque los muchachos dejan de practicar este ejercicio, tan conveniente para su desarrollo físico siempre que la luchada se realice con arreglos a normas de deportividad; un error, porque esta clase de competiciones, en que el factor personal es el preponderante, entraña una moral y una física muy convenientes para salvar los escollos de la edad peligrosa. En nuestras escuelas primarias la lucha a lo isleño debiera formar parte de su educación física y acaso sea el sEu o el Frente de Juventudes, o ambos a la vez, los llamados a recoger esta antorcha de los aborígenes para hacerla llegar hasta el fin de los tiempos ${ }^{54}$.

Esta misma cabecera, en meses posteriores, se posiciona más rotundamente y, siguiendo los pasos de la propuesta de la Federación Española de Natación respecto a esta actividad acuática, propone «que se declare la práctica obligatoria,

${ }_{51}$ «Una gran competición interescolar de lucha canaria está preparando la Federación Regional», Falange, n. ${ }^{\circ} 6903,8$ de octubre de 1952, p. 5.

52 «Languidece la lucha», Falange, n. ${ }^{\circ} 7067,22$ de abril de 1953 , p. 5.

53 Ibidem.

${ }_{54}$ «Sobre la lucha canaria», Diario de Las Palmas, n. ${ }^{\circ}$ I570I, 27 de mayo de I954, p. 6. 
LOS JUEGOS TRADICIONALES Y LA EDUCACIÓN EN CANARIAS: DE LAS PROPUESTAS

DEL SIGLO XIX A LAS REGULACIONES AUTONÓMICAS

ANTONIO S. ALMEIDA AGUIAR Y ULISES S. CASTRO NÚÑEZ

siempre que la ficha médica no aconseje lo contrario, de la lucha canaria en los centros escolares»s5.

\section{La presencia de los juegos y deportes tradicionales en el currículo de Canarias}

La llegada de la democracia a España y el establecimiento de un sistema de división territorial en torno a las autonomías favorecieron la incorporación de los juegos y deportes tradicionales en la escuela como seña de identidad. En 1979 aparece una obra que será el referente para la enseñanza de la lucha canaria: Lucha canaria para niños y principiantes ${ }^{56}$. La década de 1980 supuso un periodo de gran efervescencia en la escuela canaria; ya desde 1978 se habían iniciado las Escuelas de Verano de Canarias, que perseguían el perfeccionamiento y reciclaje de los profesores para su adaptación a las nuevas exigencias y necesidades de la enseñanza, así como la mejora de la escuela pública y la renovación pedagógica. Estos cursillos, debates, seminarios y talleres reunían durante una semana a profesorado de todo el archipiélago. Las temáticas eran diversas y pretendían responder al interés de los asistentes; iban desde la enseñanza en el preescolar hasta la educación y lectura de la imagen publicitaria, pasando por la introducción al ritmo, al juego, al drama y a la psicomotricidad, la expresión corporal, la pedagogía sexual o la enseñanza del inglés en ЕGв. Entre los talleres era habitual encontrar temas relacionados con los contenidos canarios como los telares canarios, la cestería y palma, el barro en la escuela, la talla canaria o la escuela y la lucha canaria ${ }^{57}$.

La Comunidad Autónoma de Canarias recibe de la Administración del Estado el traspaso de funciones y servicios en Educación mediante el Real Decreto 209I/1983, de 28 de julio, donde, entre las funciones del Estado que asume la comunidad autónoma, en su apartado i) establece:

La regulación de los niveles, grados, modalidades y especialidades de enseñanza y de normas y orientaciones pedagógicas, en concordancia y desarrollo de las disposiciones del Estado sobre ordenación general del sistema educativo y fijación de enseñanzas mínimas a que se refiere la disposición adicional $2^{58}$ de la Ley Orgánica 5/1980, de I9 de junio, por la que se regula el estatuto de Centros Escolares. En dicha

" «Y también la lucha canaria», Diario de Las Palmas, n. ${ }^{\circ}$ 15802, I4 de septiembre de 1954, p. 6.

56 Hernández Moreno, J. y SÁnchez García, S.: Lucha canaria para niños y principiantes, Las Palmas de Gran Canaria, Hernández Moreno, 1979.

57 B. de Q., V.: «Comienzo de la VI Escuela de Verano de Canarias», Diario de Las Palmas, 5 de julio de 1983, p. 8 .

s8 Disposición adicional dos. «En todo caso, y por su propia naturaleza, corresponde al Estado:

a) La ordenación general del sistema educativo.

b) La fijación de las enseñanzas mínimas y la regulación de las demás condiciones para la obtención, expedición y homologación de títulos académicos y profesionales válidos en todo el territorio español».

Boletin Oficial del Estado, n. ${ }^{\circ}$ I54, de 27 de junio de 1980, p. 14636. 
regulación se atenderá especialmente a lo previsto en el artículo 5.259, apartado b), del Estatuto de Autonomía de Canarias.

Esta transferencia que afecta a la capacidad del Gobierno de Canarias para influir sobre los currículos y sus contenidos, en un porcentaje que respete las enseñanzas mínimas comunes a todo el territorio español, y principalmente lo que recoge el artículo 5.2, en su apartado b), justifica de manera clara y rotunda la presencia de contenidos referidos a los juegos y deportes tradicionales en los currículos de las distintas enseñanzas no universitarias, y en aquellas universitarias que tienen la capacidad de formar a los futuros docentes de los diversos niveles educativos.

Las diferentes leyes educativas que se han ido promulgando en España durante el periodo democrático, y aquellas que se desarrollaron con posterioridad a las transferencias en Educación a la Comunidad Autónoma de Canarias, han dado lugar a diversos currículos para los diferentes niveles educativos no universitarios en los que las prácticas lúdicas y deportivas tradicionales han estado presentes de manera heterogénea. Analizaremos la primera de esas leyes, la Ley Orgánica de Ordenación del Sistema Educativo (LOGSE) ${ }^{60}$, su antecedente y la vigente, la Ley Orgánica para la Mejora de la Calidad Educativa (LOMCE) ${ }^{6}$.

El juego tradicional se recoge expresamente entre los contenidos a desarrollar dentro de los Diseños Curriculares Base ${ }^{62}$ para Canarias de I99I. El término tradicional, como se indicó con anterioridad, es el más adecuado para referirnos a las prácticas lúdicas y deportivas que se han transmitido durante generaciones, de manera continuada, dentro de un grupo o comunidad con una cierta homogeneidad sociocultural; pero no siempre se ha utilizado de modo correcto, siendo sustituido por otros como autóctono o popular, motivada esta realidad por los graves

59 «Los poderes públicos canarios, en el marco de sus competencias, asumen como principios rectores de su política:

b) La defensa de la identidad y de los valores e intereses del pueblo canario».

Boletín Oficial del Estado, n. ${ }^{\circ}$ I95, de 16 de agosto de 1982, p. 22047.

${ }_{60}$ Decreto 46/1993, de 26 de marzo, por el que se establece el currículo de la Educación Primaria, Boletin Oficial de Canarias, n. ${ }^{\circ}$ 44, viernes, 9 de abril de 1993, pp. 1914-1977.

Decreto 310/1993, de io de diciembre, por el que se establece el currículo de la Educación Secundaria Obligatoria, Boletín Oficial de Canarias, n. ${ }^{\circ}$ I2, viernes 28 de enero de 1994, pp. 542-642.

Decreto IoI/1995, de 26 de abril, por el que se establece el currículo de Bachillerato, Boletín Oficial de Canarias, n. ${ }^{\circ} 65$, jueves 25 de mayo de 1995 , pp. 4414-4569.

${ }_{61}$ Decreto $89 / 2014$, de I de agosto, por el que se establece la ordenación y el currículo de la Educación Primaria en la Comunidad Autónoma de Canarias, Boletín Oficial de Canarias, n. ${ }^{\circ}$ 156, miércoles I3 de agosto de 20I4, pp. 2191I-22582. Para el área de Educación Física 22353-22412.

Decreto 315/20I5, de 28 de agosto, por el que se establece la ordenación de la Educación Secundaria Obligatoria y del Bachillerato en la Comunidad Autónoma de Canarias, Boletín Oficial de Canarias, n. ${ }^{\circ}$ 156, lunes 3I de agosto de 20I5, pp. 25289-25335. Para el área de Educación Física 22353-224I2.

Decreto $83 / 2016$, de 4 de julio, por el que se establece el currículo de la Educación Secundaria Obligatoria y el Bachillerato en la Comunidad Autónoma de Canarias, Boletín Oficial de Canarias, n. ${ }^{\circ}$ 136, viernes is de julio de 2016, pp. 17046-19333. Para el área de Educación Física 18637-I8683.

62 Gobierno de Canarias: Diseños Curriculares. Educación Primaria. Áreas: Lenguas Extranjeras y Educación Fisica, Santa Cruz de Tenerife, Consejería de Educación, Cultura y Deportes, 1992. 
LOS JUEGOS TRADICIONALES Y LA EDUCACIÓN EN CANARIAS: DE LAS PROPUESTAS DEL SIGLO XIX A LAS REGULACIONES AUTONÓMICAS ANTONIO S. ALMEIDA AGUIAR Y ULISES S. CASTRO NÚÑEZ

errores conceptuales cometidos por parte de los elaboradores de los distintos documentos educativos o currículos ${ }^{63}$. Así, se considerarán todas las referencias que se hagan a juego o deporte autóctono, juego o deporte popular y juego o deporte tradicional.

La lectura y el análisis de los currículos de los distintos niveles educativos que emanan de la aplicación de la LOMCE en la Comunidad Autónoma Canaria constatan que los juegos y deportes tradicionales son un contenido relevante para los expertos que hicieron su diseño. El principal problema observado es que no existen orientaciones reales para los docentes. Falta el siguiente nivel de concreción que facilitaría la presencia y la aplicación en la programación de aula. Los epígrafes van apareciendo en el texto del currículo sin una clara secuenciación, casi se podría pensar que es aleatoria; utilizando términos sinónimos que sustituyen al utilizado en el curso anterior, lo que no implica una progresión, una línea en el desarrollo de la competencia, sino dar vueltas sobre lo mismo.

El currículo establece el marco en el que se va a mover el docente para desarrollar su programación y las distintas unidades de aprendizaje que la componen. Las dificultades que puede encontrar un docente a la hora de implementar el juego y el deporte tradicional como contenido en el aula, sea el nivel educativo que sea, son muy heterogéneas y de diversa naturaleza ${ }^{64}$. Los centros educativos no tienen espacios adecuados (áreas de tierra, terrero de lucha canaria, desniveles para salto del pastor, etc.); carecen de los materiales específicos para el adecuado desarrollo de las prácticas (ropas de brega para lucha canaria, lanzas para salto del pastor, bote y pelota para pelotamano, varas para el juego del palo, etc.), y no cuentan con materiales audiovisuales o didácticos para todas las modalidades.

A estas dificultades tangibles habría que añadir otra de mayor calado: la escasa formación de los docentes en este contenido específico. Aunque las titulaciones universitarias que capacitan para impartir docencia en Educación Primaria y Eso han contado, y cuentan en algunos casos, con materias en sus planes de estudio donde se pueden adquirir estos conocimientos, los cambios que también han sufrido los currículos universitarios con la entrada en el Espacio Europeo de Educación Superior generaron que, en algunos casos, estas materias quedaran marginadas en cuanto al número de créditos, o desaparecieran totalmente.

Las Administraciones Públicas, sobre todo las educativas y deportivas, han intentado paliar esta debilidad organizando cursos y seminarios, como el denominado Propuestas metodológicas para la enseñanza de los juegos y deportes autóctonos y tradicionales canarios, que también dio lugar a una publicación ${ }^{65}$, en los

${ }_{3}$ Castro, U.: Los juegos y los deportes tradicionales de Canarias en la Educación Física Escolar, en Hernández Moreno, J.; Rodríguez Ribas, J. P.; Ramírez, V.; Quiroga, M. y Castro, U. (coords.): ACCAFIDE, Educación Física Escolar y Deporte de Alto rendimiento, Las Palmas de Gran Canaria, 1998, pp. II3-I32.

${ }^{64}$ Castro, U.: «Los juegos y los deportes tradicionales de Canarias en la Educación Física Escolar...», op. cit., p. I24.

${ }_{5}$ vv. AA.: Propuestas metodológicas para la enseñanza de los juegos y deportes autóctonos y tradicionales canarios, Las Palmas de Gran Canaria, Consejería de Educación, Cultura y Deportes del Gobierno de Canarias, 1997. 


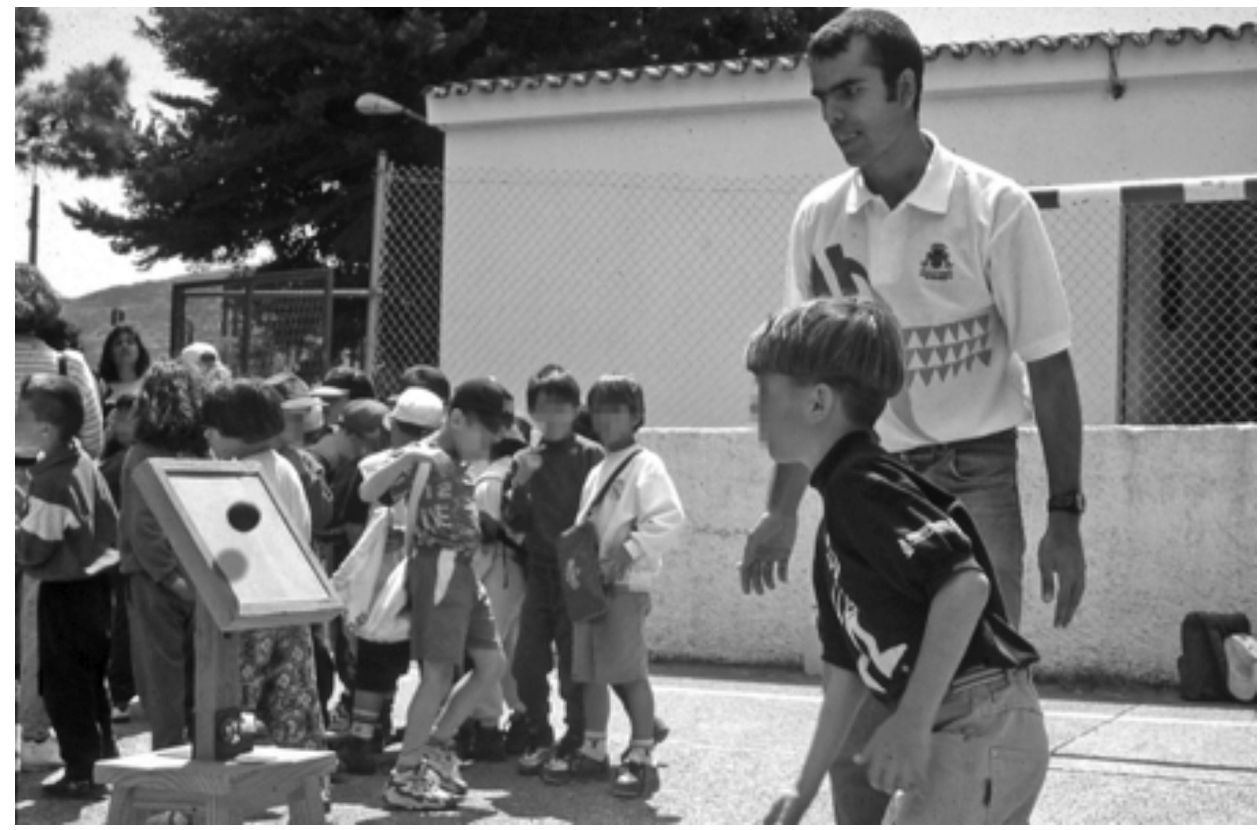

IMAgen 7: Pelotamano en un centro educativo de primaria.

Archivo: Colección Ulises Castro Núñez.

Centros de Profesores de todas las islas. O con la celebración, iniciadas en 1994, de las Muestras Escolares de los Juegos y Deportes Autóctonos y Tradicionales, orientadas principalmente a los alumnos de $5 .^{\circ}$ y $6 .^{\circ}$ de Primaria y r. ${ }^{\circ}$ y $2 .^{\circ}$ de ESO, y en las que los participantes iban pasando por diversas estaciones que se correspondían con los distintos juegos o deportes tradicionales, y en las que se les explicaba la actividad y tenían la posibilidad de interactuar con los materiales de juego e incluso practicarlos.

Otra experiencia educativa ha sido el programa del Cabildo Insular de Fuerteventura No olvides lo nuestro, iniciado en el año 2000. Este acoge parte de las prácticas ludicodeportivas de carácter tradicional de Canarias: lucha canaria, palo canario (vara y lata), bola canaria, salto del pastor, levantamiento del arado, levantamiento y pulseo de la piedra, calabazo, tiro y esquive de piedras, pelotamano, billarda, pina y tángana. La elección de las actividades estuvo condicionada por las posibilidades espaciales y materiales, la complejidad de su desarrollo, la presencia social de las distintas prácticas y la formación de los monitores. Quizás podríamos valorar la rigurosidad al incluir el calabazo o el tiro y esquive de piedras, pero en este último caso se podría justificar por la importancia social y económica que ha tenido y tiene la ganadería caprina en la isla de Fuerteventura ${ }^{66}$.

66 Castro, U.: «Los juegos y deportes tradicionales de Canarias. Una realidad social y cultural del siglo XXI», en Dueñas, E. X. (ed.): Juegos, Deportes e Investigación folclórica, Donostia, Eusko Ikaskutza, 2009. 
LOS JUEGOS TRADICIONALES Y LA EDUCACIÓN EN CANARIAS: DE LAS PROPUESTAS

DEL SIGLO XIX A LAS REGULACIONES AUTONÓMICAS

ANTONIO S. ALMEIDA AGUIAR Y ULISES S. CASTRO NÚÑEZ

El programa No olvides lo nuestro es el único que se mantiene en la actualidad. El resto ha desaparecido por motivos económicos, por no haber renovado los objetivos y características del proyecto o por el desinterés de las autoridades políticas y educativas.

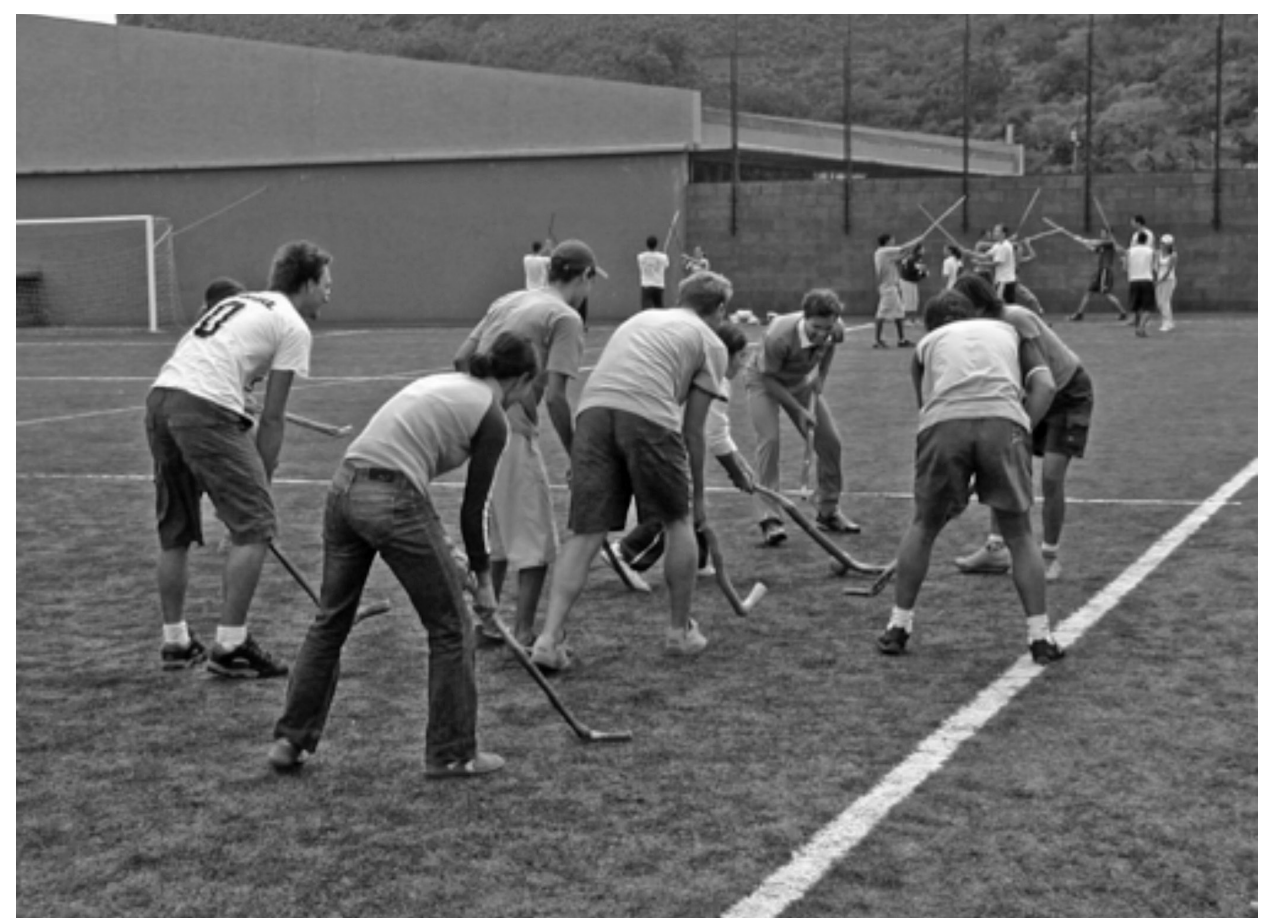

Imagen 8: Juego de la pina. Archivo: Colección Ulises Castro Núñez.

En el curso 2017-20I8, la Dirección General de Deportes e Innovación Educativa pone en marcha dos proyectos para la divulgación y promoción de los juegos y deportes tradicionales en los centros educativos: La lucha canaria entra en la escuela, orientado al acercamiento del alumnado de $5 .^{\circ}$ y $6 .^{\circ}$ de Educación Primaria a la lucha canaria, y Los juegos y deportes autóctonos y tradicionales, que pretende la familiarización del estudiantado de $3 .^{\circ}$ y $4 .^{\circ}$ de Educación Primaria con algunas de las prácticas que completan el catálogo lúdico tradicional de Canarias (juego del palo, lucha del garrote, barquillos y botes de vela latina, arrastre de ganado, salto del pastor y bola canaria).

\section{Conclusiones}

Los docentes siempre han visto en el juego motor tradicional, principalmente el juego tradicional infantil, una actividad con un significativo valor educativo 
y de motivación. En un principio, en las Islas se utilizan de manera genérica los juegos como elemento de innovación educativa, como referente de cambio entre la escuela tradicional y la escuela nueva. De ahí que muchos discursos recogidos en la prensa centren su interés en los juegos didácticos, que en el cambio de centuria se convirtieron en grandes novedades educativas. Por otra parte, el juego se identifica en el cambio de siglo como parte integral de la enseñanza gimnástica, alcanzando así un nivel normativo y orientador de las prácticas físicas. El juego aparece en este contexto como la base primaria de la educación física, con un fin pragmático, basado en teorías y principios prácticos que beneficiarían a la educación de la infancia. En otros casos, el juego se relaciona más con su función catártica y de gastos de excedente de energía que con su vinculación a la gimnasia. En estos inicios, por tanto, las propuestas se debaten en ocasiones entre el componente de libertad del juego frente al componente racional o científico de la gimnasia.

Sin embargo, de manera progresiva, la diversidad del juego se va concretando en la utilización del juego tradicional no solo como elemento educativo, sino como instrumento de identidad cultural. Así se desprende incluso de la normativa que, a través de los reales decretos, va configurando la enseñanza de la gimnástica a finales del siglo XIx. En este contexto, ya se recomienda la selección de juegos tradicionales para revalorizar la tradición lúdica española frente a otros juegos exportados, principalmente en referencia a los sports británicos. El ejemplo más significativo de este planteamiento en el archipiélago es la lucha canaria. En el imaginario idealizado de la población insular, reúne una serie de características que la relacionan con la población indígena canaria preeuropea: valor, nobleza y estética motriz. Esta y otras razones han hecho que sea la práctica deportiva tradicional más popular y característica del catálogo de los juegos y deportes tradicionales del Archipiélago Canario, y la que más implementación ha tenido en la escuela.

Los juegos y deportes tradicionales han sido valorados como una seña de identidad, en la etapa del franquismo, como elemento diferenciador de «lo español» frente al deporte universal que venía del exterior y que no tenía los valores de las prácticas tradicionales «patrias». En la etapa democrática, como elemento distintivo frente a los otros territorios que conforman España, podríamos hablar de una «identificación» interna. El uso de los adjetivos autóctono, popular o tradicional, asociados al juego o al deporte, tanto en la prensa escrita como en los documentos educativos, no sigue ningún criterio de rigor; observamos cómo en los últimos documentos ha ido desapareciendo la utilización de autóctono y se prioriza el de tradicional, principalmente en los textos que emanan de la administración educativa. Los juegos y deportes tradicionales de Canarias se han visto favorecidos con la creación de la Comunidad Autónoma Canaria y la transferencia de Educación al Gobierno canario; de esta forma han sido incluidos de manera relevante entre los contenidos a impartir en los distintos niveles educativos. Razones de tipo material, espacial, recursos metodológicos y de formación de los docentes han dificultado la implementación real y adecuada de estas prácticas en el aula. 